\title{
Evaluasi Ekstraksi Molar Ketiga Rahang Bawah Berdasarkan Angulasi Mesial pada Radiografi Panoramik
}

\author{
Rosalina I. Saputri, ${ }^{1}$ Rizky M. Boedi ${ }^{2}$
}

\author{
${ }^{1}$ Fakultas Kedokteran Gigi Universitas Kristen Maranatha Bandung \\ ${ }^{2}$ Departemen Kedokteran Gigi Fakultas Kedokteran Universitas Diponegoro Semarang \\ Email: rosalina.saputri@gmail.com
}

\begin{abstract}
Third molar development is a concern in dental care because of its influence on stomatognathic system. Due to third molar irregular pattern of eruption, different clinical and radiographic considerations on how to decide an extraction were studied. This study was aimed to evaluate the effect of mandibular third molar mesial angulation (MA) towards the extractions on panoramic radiographs. This was a retrospective study. A longitudinal study of mandibular third molars ( $\mathrm{n}=192)$ of 102 individuals (50 Female and 52 Male) was conducted. Development of the mandibular third molar was staged according to modified Köhler et al. staging technique. Mesial angulation was measured from the intersection between axes of third molar and adjacent second molar of the most developed stage for extraction cases or before root completion for nonextraction cases. Of 102 subjects, 107 mandibular third molars were extracted. The increase of $1^{\circ}$ of MA would increase the odds ratio (OR) of extraction by 1.113 (95\% CI 1.070-1.158, p<0.01). The ROC curve showed the MA of $18.5^{\circ}$ as the threshold of extraction with $76 \%$ of sensitivity and $68 \%$ of specificity. In conclusion, MA has the possibility as a predictive factor of mandibular third molar extraction. Future studies using bigger sample sizes and variations of third molar development are suggested
\end{abstract}

Keywords: third molar, angulation, extraction, predictive factor, panoramic radiographs

\begin{abstract}
Abstrak: Pertumbuhan molar ketiga menjadi perhatian pada perawatan dental karena pengaruhnya pada sistem stomatognasi. Terdapat banyak penelitian tentang berbagai pertimbangan klinis dan radiografis untuk melakukan ekstraksi molar ketiga karena pola erupsinya yang tidak menentu. Penelitian ini bertujuan untuk mengevaluasi efek angulasi mesial (AM) dari molar ketiga rahang bawah terhadap tindakan ekstraksi pada radiografi panoramik. Jenis penelitian ialah retrospektif. Pengamatan molar ketiga rahang bawah $(n=192)$ secara longitudinal dilakukan pada 102 individu (50 perempuan dan 52 laki-laki). Pertumbuhan molar ketiga diukur berdasarkan tahap pertumbuhan dari teknik modifikasi Köhler et al. AM diukur dari pertemuan aksis molar ketiga dan molar kedua di sebelahnya, pada tahap pertumbuhan paling akhir pada kasus ekstraksi, atau sebelum akar gigi terbentuk sempurna pada kasus non-ekstraksi. Pada sampel penelitian, ekstraksi dilakukan pada 104 molar ketiga rahang bawah. Peningkatan $1^{\circ}$ dari AM akan meningkatkan rasio peluang dari ekstraksi sebesar 1,113 (95\% CI 1,070-1,158, p<0,01). Pada kurva ROC, AM sebesar $18,5^{\circ}$ menunjukan $76 \%$ sensitivitas dan $68 \%$ spesifisitas. Simpulan penelitian ini ialah AM dapat digunakan sebagai faktor prediksi terhadap ekstraksi molar ketiga rahang bawah. Perkembangan penelitian selajutnya dapat dilakukan dengan jumlah sampel yang lebih besar dan dengan memperhatikan pertimbahan klinis serta parameter radiografik lainnya.
\end{abstract}

Kata kunci: molar ketiga, angulasi, ekstraksi, faktor prediksi, radiografi panoramik

\section{PENDAHULUAN}

Molar ketiga merupakan gigi yang paling akhir erupsi yaitu pada usia antara 17-
26 tahun. $^{1}$ Oleh karena itu, molar ketiga sering mempunyai ruang tempat erupsi yang terbatas sehingga tidak berhasil erupsi atau 
hanya erupsi sebagian, yang disebut dengan impaksi. ${ }^{1,2}$ Impaksi molar ketiga dapat menyebabkan pembengkakan dan ulserasi pada gusi, atau perikoronitis, karies dan kerusakan akar molar kedua, serta kerusakan jaringan lunak serta keras disekitarnya., Molar ketiga yang memiliki gejala dari gangguan-gangguan tersebut disarankan untuk dilakukan ekstraksi. ${ }^{1,3}$ Namun, prosedur ekstraksi molar ketiga, atau yang disebut odontektomi, memiliki berbagai komplikasi, antara lain rasa nyeri, pembengkakan, dry socket, parestesia, perdarahan, infeksi, sisa akar yang tertinggal, dan trismus.,6

Berdasarkan sudut pandang penatalaksanaan preventif, untuk mecengah terjadinya gejala dari impaksi molar ketiga dan mencegah komplikasi pada prosedur pencabutan yang lebih parah, ekstraksi profilaksis dari molar ketiga dapat menjadi pilihan sebelum molar ketiga mengalami pertumbuhan lebih lanjut dan mengalami gejala impaksi. ${ }^{7,8}$ Namun sebaliknya, beberapa penelitian mengungkapkan alasan untuk tetap mempertahankan molar ketiga yang tidak mengalami gejala. ${ }^{1,9}$ Dalam studinya, Venta $^{3}$ hanya memberikan dua kontraindikasi ekstraksi molar ketiga, yaitu: 1) gigi yang tidak dapat erupsi, namun tidak mengalami gangguan dan dalam keadaan sehat, dan 2) ekstraksi akan menyebabkan risiko pada kesehatan lokal dan umum pasien. ${ }^{3}$

Berkaitan dengan pertimbangan ekstraksi atau mempertahankan molar ketiga, beberapa penelitian dilakukan untuk menentukan prediksi kemungkinan erupsi dari molar ketiga, termasuk pengukuran parameter pada radiograf. ${ }^{10,11}$ Angulasi molar ketiga, terutama pada rahang bawah, ialah salah satu parameter yang dapat memengaruhi kemungkinan erupsi molar ketiga. ${ }^{12,13}$ Selain itu, sudut angulasi dari molar ketiga juga dapat digunakan untuk memrediksi ketebalan dinding tulang lingual mandibula, penyakit periodontal, dan relasinya terhadap syaraf kanalis mandibula. ${ }^{12,14,15}$ Tujuan penelitian ini ialah melakukan evaluasi terhadap salah satu parameter, yaitu angulasi antara aksis molar ketiga rahang bawah dengan molar kedua pada regio yang sama, pada penelitian ini disebut sebagai angulasi mesial (AM), yang diamati pada radiografi panoramik terhadap kemungkinan tindakan ekstraksi.

\section{METODE PENELITIAN}

Radiograf panoramik dari 102 individu (50 wanita dan 52 laki-laki) dengan usia antara 12,98-23,36 tahun dipilih secara retrospektif dari klinik pribadi dokter gigi. Pertumbuhan molar ketiga diukur berdasarkan tahap pertumbuhan dari modifikasi Köhler et al. (stage 1-10). ${ }^{16}$ Kriteria inklusi dari individu ialah memiliki paling sedikit dua radiografi panoramik yang diambil pada waktu berbeda dalam rentang tertentu dengan salah satu molar ketiga rahang bawah yang dicabut atau dipertahankan setelah tahap pembentukan akar gigi (> stage 4). Kriteria ekslusi ialah kualitas gambar radiograf yang tidak dapat diamati, terdapat kelainan pertumbuhan, dan hanya mempunyai molar ketiga dengan angulasi selain ke arah mesial (distal/buccal/lingual).

Pengamatan secara longitudinal dilakukan pada molar ketiga dari tahap partumbuhan stage 4-7 hingga molar ketiga tersebut dicabut (ekstraksi) atau dipertahankan (non-ekstraksi). Gambar 1 memperlilhatkan angulasi mesial (AM) diukur berdasarkan pertemuan dua garis khayal yang ditarik dari axis molar ketiga dan molar kedua di regio yang sama.

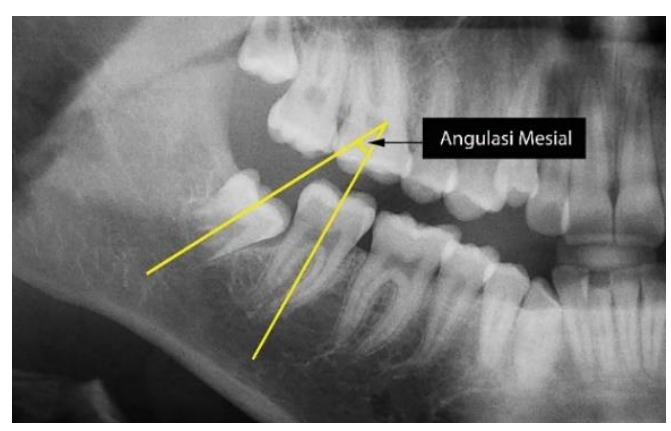

Gambar 1. Skema pengukuran angulasi mesial (AM) pada molar ketiga rahang bawah. Garis kuning menunjukan aksis dari molar ketiga dan molar kedua. AM adalah sudut pertemuan dari kedua aksis tersebut.

Nilai AM pada kasus ekstraksi diamati pada tahap pertumbuhan paling akhir dari 
radiografi panoramik yang diambil sebelum ekstraksi, sedangkan nilai AM pada kasus non-ekstraksi diamati pada tahap pertumbuhan sebelum akar gigi terbentuk sempurna (<stage 10). Analisis regresi logistik dilakukan pada nilai AM kelompok ekstraksi dan non-ekstraksi. Selanjutnya, analisis kurva Receiver Operating Characteristic (ROC) dan Area Under Curve (AUC) dilakukan untuk menilai kemampuan AM untuk menentukan dua kelompok diagnosis, dalam penelitian ini adalah ekstraksi, dan non-ekstraksi. ${ }^{17}$

\section{HASIL PENELITIAN}

Dari 102 subyek, terdapat 104 molar ketiga yang diekstraksi dan 88 molar ketiga yang tidak dilakukan ekstraksi. Tabel 1 memperlihatkan bahwa tidak terdapat perbedaan bermakna pada jenis kelamin dan usia subyek penelitian terhadap tindakan ekstraksi/non-ekstraksi. Rerata usia pada kelompok ekstraksi ialah 15,75 tahun ( $\mathrm{SD}=$
1,80 tahun) dan pada kelompok nonekstraksi 16,24 tahun ( $\mathrm{SD}=2,30$ tahun).

Tabel 2 memperlihatkan bahwa sebagian besar tahap pertumbuhan pada kelompok ekstraksi ialah pada stage 5 dan stage 6, sedangkan pada kelompok non-ekstraksi ialah stage 6 dan stage 7 .

Tabel 3 memperlihatkan nilai AM minimal dan maksimal dari kelompok ekstraksi maupun non-ekstraksi. Rerata angulasi mesial (AM) kelompok ekstraksi ialah $24,89^{\circ}$ dan kelompok non-ekstraksi ialah $17.36^{\circ}$. Regresi logistik menunjukan peningkatan $1^{\circ}$ dari AM akan menambah rasio peluang (odds ratio-OR) dari ekstraksi sebesar 1,11 (dengan 95\% CI 1,07-1,16).

Gambar 2 memperlihatkan kurva ROC yang menunjukkan nilai AUC sebesar 0,75 yang bermakna secara statistik $(\mathrm{p}<0,01)$. Ambang batas AM sebesar $18,5^{\circ}$ menunjukkan $76 \%$ sensitivitas dan $68 \%$ spesifisitas.

Tabel 1. Karakteristik dasar subyek penelitian berdasarkan jenis kelamin dan usia

\begin{tabular}{lccc}
\hline & Ekstraksi & Non-ekstraksi & Nilai signifikansi \\
\hline Jenis kelamin $(\mathrm{n})$ & & & \\
$\quad$ Perempuan & 31 & 19 & \\
Laki-laki & 23 & 29 & $\mathrm{p}=0,07$ \\
$\quad$ Total & 54 & 48 & \\
Rerata usia (tahun) & & & \\
$\quad$ Perempuan & $15,66(\mathrm{SD}=1,51)$ & $15,74(\mathrm{SD}=3,33)$ & \\
Laki-laki & $15,87(\mathrm{SD}=2,16)$ & $16,57(\mathrm{SD}=1,23)$ & $\mathrm{p}=0,79$ \\
Total & $15,75(\mathrm{SD}=1,80)$ & $16,24(\mathrm{SD}=2,31)$ & \\
\hline
\end{tabular}

Tabel 2. Jumlah molar ketiga pada kelompok ekstraksi dan kelompok non-ekstraksi berdasarkan tahap pertumbuhan menurut modifikasi Köhler et al.

\begin{tabular}{ccc}
\hline $\begin{array}{c}\text { Tahap pertumbuhan } \\
\text { (stage) }\end{array}$ & \multicolumn{2}{c}{ Molar ketiga (n) } \\
Ekstraksi & Non-ekstraksi \\
\hline 4 & 4 & 0 \\
5 & 42 & 13 \\
6 & 32 & 25 \\
7 & 24 & 46 \\
8 & 2 & 2 \\
9 & 0 & 2 \\
Total & 104 & 88 \\
\hline
\end{tabular}


Tabel 3. Angulasi mesial dari molar ketiga pada kelompok ekstraksi dan non ekstraksi

\begin{tabular}{lccc}
\hline & \multicolumn{3}{c}{ Angulasi Mesial } \\
& Min. & Mean & Max. \\
\hline Ekstraksi & $4^{\circ}$ & $24,89^{\circ}$ & $45^{\circ}$ \\
Non-ekstraksi & $5^{\circ}$ & $17,36^{\circ}$ & $40^{\circ}$ \\
\hline
\end{tabular}

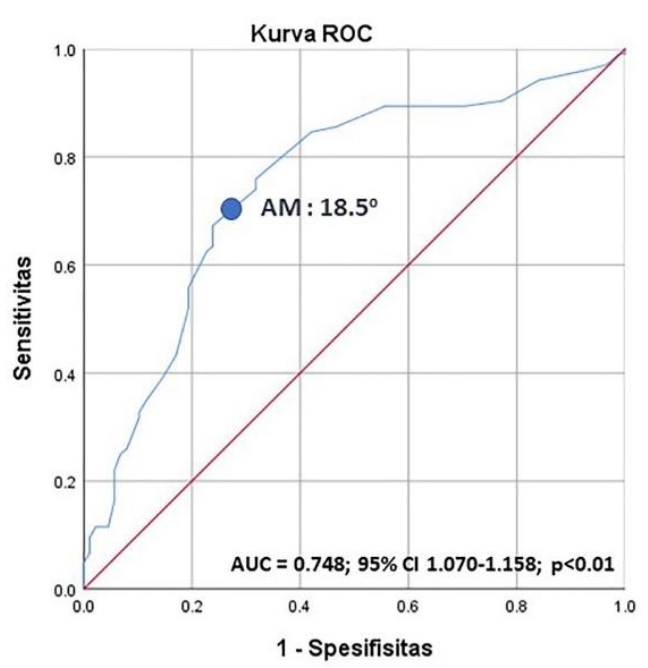

Gambar 2. Kurva ROC dari AM molar ketiga rahang bawah berdasarkan tindakan ekstraksi/ non-ekstraksi (garis biru). Nilai batas (cut-off) $\mathrm{AM}$ pada $18,5^{\circ}$ ditunjukan oleh titik biru. $\mathrm{AM}=$ Angulasi Mesial, AUC = Area Under Curve, CI $=$ Confidence Interval.

\section{BAHASAN}

Erupsi molar ketiga merupakan proses yang kompleks, membutuhkan waktu beberapa tahun, dan sering tanpa gelaja, yang menyebabkan tindakan ekstraksi menjadi pertimbangan yang meragukan bagi para klinisi. ${ }^{3,18}$ Namun hingga saat ini, ekstraksi molar ketiga masih menjadi prosedur pembedahan dentoalveolar yang paling umum. ${ }^{19} \mathrm{Hal}$ ini dilakukan karena impaksi dari molar ketiga dan proses erupsinya menyebabkan berbagai kondisi patologik pada $75 \%$ kasus. ${ }^{20}$ Oleh karena itu, ekstraksi molar ketiga dapat menurunkan faktor risiko dari beberapa penyakit rongga mulut (karies, infeksi, kista, tumor, abses, dan kelainan sendi termporomandibula) dan meningkatkan efisiensi mastikasi karena kegunaan molar ketiga yang dianggap minimal dalam proses pengunyahan. ${ }^{21-23}$
Di sisi lain, perdebatan etik timbul dalam hal ekstraksi pada molar ketiga yang bersifat profilaksis. Friedman et $\mathrm{al}^{24}$ berpendapat bahwa ekstraksi profilaksis berdampak pada kesehatan masyarakat dalam hal trauma iatrogenik. Hal ini juga didukung oleh Adeyemo et $\mathrm{al}^{25}$ yang menyatakan bahwa ekstraksi profilaksis harus dibatasi dan pengambilan keputusan ekstraksi profilaksis harus berdasarkan kondisi individu dan tidak berdasarkan pada keadaan populasi masyarakat secara umum. Pendapat tersebut dibuktikan oleh McNamara et $\mathrm{al}^{26}$ yang menuliskan tingginya angka trauma yang disebabkan oleh prosedur ekstraksi pada pasien ekstraksi profilaksis dan non-ekstraksi profilaksis $(\mathrm{p}<0,038)$. Hasil penelitian ini diharapkan mampu membantu memberikan pertimbangan untuk melakukan diagnosis individual, terutama dalam prosedur ekstraksi profilaksis. Namun, pertimbangan tersebut tetap harus disertai dengan kondisi klinis yang didapatkan melalui pemeriksaan obyektif dokter gigi yang melakukan perawatan.

Berbagai parameter telah digunakan untuk memrediksi erupsi dari molar ketiga dan pertimbangan untuk mempertahankannya, salah satunya ialah angulasi yang diukur dari perpotongan aksis antara molar ketiga dan molar kedua mandibula pada regio yang sama (Angulasi Mesial/AM). Salah satu penelitian yang paling awal ialah penelitian dari Haavikko et $\mathrm{al}^{27}$ yang menyebutkan bahwa kemungkinan molar ketiga rahang bawah untuk erupsi ialah 1 dari 3 kasus jika memiliki AM di antara $20^{\circ}$ $30^{\circ}$. Nance et al ${ }^{15}$ menyatakan dalam studinya bahwa $11 \%$ dari molar ketiga rahang bawah akan erupsi jika memiliki $\mathrm{AM} \geq 25^{\circ}$ dan hanya 3\% akan erupsi jika $\mathrm{AM} \geq 35^{\circ}$. Penelitian dari Vranckx et al $^{12}$ menunjukan bahwa molar ketiga dengan sudut $A M \geq 27^{\circ}$ memiliki kemampuan yang minimal untuk erupsi. Walaupun memiliki batas nilai AM yang berbeda-beda, berbagai penelitian sebelumnya sepakat bahwa semakin besar AM maka kemampuan erupsi akan semakin kecil. Hal ini tercermin pada penelitian ini dengan peningkatan OR ekstraksi seiring dengan peningkatan AM. Penelitian ini juga 
mencoba memresentasikan sensitivitas dan spesifisitas dari batas nilai AM yang dianggap paling optimal jika digunakan sebagai pemeriksaan pendukung dalam tindakan ekstraksi.

Perubahan posisi dan angulasi dari molar ketiga yang masih dapat terjadi hingga pertumbuhan gigi tersebut selesai. ${ }^{15,28}$ Penelitian Hattab ${ }^{29}$ menunjukkan bahwa hampir $80 \%$ molar ketiga megalami perubahan kemiringan menjadi lebih vertikal atau mesial selama empat tahun partumbuhan. Namun Richardson ${ }^{30}$ menyebutkan tidak terjadi perubahan bermakna pada angulasi molar ketiga pada penelitian yang dilakukan terhadap populasi berusia 18 tahun (rerata perubahan $3,13^{\circ}$ ). Pada penelitian ini, molar ketiga diobservasi setelah akar telah terbentuk (>stage 4 ) hingga molar ketiga diekstraksi atau sebelum akar terbentuk sempurna untuk mendapatkan nilai AM pada tahap pertumbuhan paling akhir sebelum tindakan ekstraksi/nonekstraksi. Namun, ekstraksi molar ketiga pada penelitian ini sebagian besar dilakukan pada stage $5(40,38 \%)$ dan stage $6(30,77 \%)$ sehingga perubahan angulasi setelah tahap tersebut tidak diperhitungkan.

\section{SIMPULAN}

Angulasi mesial (AM) berpotensi untuk digunakan sebagai faktor prediksi terhadap penentuan perawatan ekstraksi pada molar ketiga rahang bawah.

Disarankan untuk penelitian selanjutnya agar meningkatkan akurasi pengukuran AM dengan jumlah sampel yang lebih besar dan variasi dari pertumbuhan molar ketiga pada sampel yang lebih beragam. Pemeriksaan terhadap kondisi klinis molar ketiga pasien juga perlu dilakukan selain pemeriksaan radiografis untuk memperkuat pertimbangan ekstraksi/non-ekstraksi. Selain itu, integrasi dari parameter lain seperti ketersediaan ruang dari retromolar, dapat menjadi informasi yang mendukung memrediksi pertumbuhan molar ketiga.

\section{Ucapan Terima Kasih}

Penulis mengucapkan terima kasih kepada dr. Winardi E. Setiawan untuk saran terkait metode analisis statistik penelitian ini.

\section{Konflik Kepentingan}

Penulis menyatakan tidak terdapat konflik kepentingan dalam studi ini.

\section{DAFTAR PUSTAKA}

1. Ghaeminia H, Perry J, Nienhuijs ME, Toedtling V, Tummers M, Hoppenreijs TJM, Van der Sanden WJM, Mettes TG. Surgical removal versus retention for the management of asymptomatic diseasefree impacted wisdom teeth. Cochrane Database Syst Rev. 2016;8:CD003879 1-29.

2. Yilmaz HG, Bayindir H. Clinical evaluation of chlorhexidine and essential oils for adjunctive effects in ultrasonic instrumentation of furcation involvements: a randomized controlled clinical trial. Int J Dent Hyg. 2012;10(2):113-7.

3. Ventä I. Current care guidelines for third molar teeth. J Oral Maxillofac Surg. 2015; 73(5):804-5.

4. Syed KB, Alshahrani FS, Alabsi WS, Alqahtani ZA, Hameed MS, Mustafa AB, Alam T. Prevalence of distal caries among mandibular second molar due to impacted third molar teeth. J Clin Diagnostic Res. 2017;11(3):ZC28-ZC30.

5. Lee CTY, Zhang S, Leung YY, Li SKY, Tsang $\mathrm{CC}, \mathrm{Chu} \mathrm{CH}$. Patients' satisfaction and prevalence of complications on surgical extraction of third molar. Patient Prefer Adherence. 2015;9:257-63.

6. Aravena P, Veláquez RAC, Rosas CF. Signs and symptoms of postoperative complications in third molar surgery: A literature review. J Int Dent Med Res. 2015;8(3):140-6.

7. Alves-Pereira D, Pereira-Silva D, Figueiredo R, Gay-Escoda C, Valmaseda-Castellón E. Clinician-related factors behind the decision to extract an asymptomatic lower third molar. A cross-sectional study based on Spanish and Portuguese dentists. Med Oral Patol Oral Cir Bucal. 2017;22(5):e609-e615.

8. Kim SJ, Hwang CJ, Park JH, Kim HJ, Yu HS. Surgical removal of asymptomatic impacted third molars: Considerations for orthodontists and oral surgeons. Semin Orthod. 2015;22(1):75-83.

9. De Bruyn L, Vranckx M, Jacobs R, Politis C. A retrospective cohort study on reasons to 
retain third molars. Int J Oral Maxillofac Surg. 2019; YIJOM-4300:1-6.

10. Bastos A do C, de Oliveira JB, Mello KFR, Leão PB, Artese F, Normando D. The ability of orthodontists and oral/ maxillofacial surgeons to predict eruption of lower third molar. Prog Orthod. 2016;17(1):21-6.

11. Kumar SP, Guptan M, Shenai KP, Chatra L. Suresh KV. Panoramic radiograph as a diagnostic tool for the prediction of mandibular third molar eruption. Int J Maxillofac Imaging. 2016;2(1):17-21.

12. Vranckx M, Ockerman A, Coucke W, Claerhout E, Grommen B, Miclotte A, Van Vlierberghe M, Politis C, Jacobs R. Radiographic prediction of mandibular third molar eruption and mandibular canal involvement based on angulation. Orthod Craniofacial Res. 2019;22(2): 118-23.

13. Kaur R, Kumar AC, Garg R, Sharma S, Rastogi T, Gupta VV. Early prediction of mandibular third molar eruption/ impaction using linear and angular measurements on digital panoramic radiography: A radiographic study. Indian J Dent. 2016;7(2):66-9.

14. Tolstunov L, Brickeen M, Kamanin V, Susarla SM, Selvi F. Is the angulation of mandibular third molars associated with the thickness of lingual bone? Br J Oral Maxillofac Surg. 2016;54(8):914-9.

15. Nance PE, White RP, Offenbacher S, Phillips C, Blakey GH, Haug RH. Change in third molar angulation and position in young adults and follow-up periodontal pathology. J Oral Maxillofac Surg. 2006;64(3):424-28.

16. Köhler S, Schmelzte R, Loitz C, Püschel K. Die entwicklung des weisheitszahnes als kriterium der lebensaltersbestimmung. Ann Anat. 1994;176(4): 339-45.

17. Zweig MH, Campbell G. Receiver-operating characteristic (ROC) plots: A fundamental evaluation tool in clinical medicine. Clin Chem. 1993;39(4):561-77.

18. Shaweesh AI. Timing of clinical eruption of third molars in a Jordanian population. Arch Oral Biol. 2016;72:157-63.

19. Grossi GB, Maiorana C, Garramone RA, Borgonovo A, Creminelli L, Santoro F. Assessing postoperative discomfort after third molar surgery: a prospective study. J Oral Maxillofac Surg. 2007; 65(5):901-17.

20. Campbell JH. Pathology associated with the third molar. Oral Maxillofac Surg Clin North Am. 2013;25(1):1-10.

21. Claudia A, Barbu HM, Adi L, Gultekin A, Reiser V, Gultekin P, Mijiritsky E. Relationship between third mandibular molar angulation and distal cervical caries in the second molar. J Craniofac Surg. 2018;29(8):2267-71.

22. Sarikov R, Juodzbalys G. Inferior alveolar nerve injury after mandibular third molar extraction: a literature review. J Oral Maxillofac Res. 2014;5(4):e1 1-15.

23. Konstantinova D, Nenova-Nogalcheva A, Pechalova P. Early postoperative masticatory efficiency after surgical extraction of a partially impacted mandibular third molar. Acta Medica Bulg. 2019;46(2):25-9.

24. Friedman JW. The prophylactic extraction of third molars: a public health hazard. Am J Public Health. 2007;97(9):1554-9.

25. Adeyemo WL. Do pathologies associated with impacted lower third molars justify prophylactic removal? A critical review of the literature. Oral Surg Oral Med Oral Pathol Oral Radiol Endod. 2006;102(4):448-52.

26. McNamara Z, Findlay G, O'Rourke P, Batstone M. Removal versus retention of asymptomatic third molars in mandibular angle fractures: a randomized controlled trial. Int $\mathbf{J}$ Oral Maxillofac Surg. 2016;45(5):571-4.

27. Haavikko K, Altonen M, Mattila K. Predicting angulational development and eruption of the lower third molar. Angle Orthod. 1978;48(1):39-48.

28. Ventä I, Turtola L, Ylipaavalniemi P. Radiographic follow-up of impacted third molars from age 20 to 32 years. Int $\mathbf{J}$ Oral Maxillofac Surg. 2001;30(1):54-7.

29. Hattab FN. Positional changes and eruption of impacted mandibular third molars in young adults. A radiographic 4-year follow-up study. Oral Surg Oral Med Oral Pathol Oral Radiol Endod. 1997;8(4):604-8.

30. Richardson M. Changes in lower third molar position in the young adult. Am J Orthod Dentofac Orthop. 1992;102(4):320-7. 